\title{
Application of biomedical informatics to chronic pediatric diseases:
} a systematic review

\author{
Fatemeh Moeinedin 1 , Rahim Moineddin'2,3, Alejandro R Jadad ${ }^{3,4,5}$, \\ Jemila S Hamid ${ }^{1}$, Teresa To ${ }^{1,3,4}$ and Joseph Beyene* 1,3,4
}

\begin{abstract}
Address: ${ }^{1}$ Child Health Evaluative Sciences, Hospital for Sick Children, Toronto, Ontario, Canada, ${ }^{2}$ Department of Community and Family Medicine, University of Toronto, Toronto, Ontario, Canada, ${ }^{3}$ Dalla Lana School of Public Health, University of Toronto, Toronto, Ontario, Canada, ${ }^{4}$ Department of Health Policy Management and Evaluation, University of Toronto, Toronto, Ontario, Canada and ${ }^{5}$ Centre for Global eHealth Innovation, University of Toronto and University Health Network, Toronto, Ontario, Canada
\end{abstract}

Email: Fatemeh Moeinedin - moeinedin@gmail.com; Rahim Moineddin - rahim.moineddin@utoronto.ca; Alejandro R Jadad - ajadad@ehealthinnovation.org; Jemila S Hamid - jemila@utstat.toronto.edu; Teresa To - teresa.to@sickkids.ca; Joseph Beyene* - joseph@utstat.toronto.edu

* Corresponding author

Published: 5 May 2009

BMC Medical Informatics and Decision Making 2009, 9:22 doi:10.1 186/1472-6947-9-22
Received: 18 December 2008

Accepted: 5 May 2009

This article is available from: http://www.biomedcentral.com/1472-6947/9/22

(c) 2009 Moeinedin et al; licensee BioMed Central Ltd.

This is an Open Access article distributed under the terms of the Creative Commons Attribution License (http://creativecommons.org/licenses/by/2.0), which permits unrestricted use, distribution, and reproduction in any medium, provided the original work is properly cited.

\begin{abstract}
Background: Chronic diseases affect millions of children worldwide leading to substantial disease burden to the children and their families as well as escalating health care costs. The increasing trend in the prevalence of complex pediatric chronic diseases requires innovative and optimal delivery of care. Biomedical informatics applications play an important role in improving health outcomes while being costeffective. However, their utility in pediatric chronic diseases has not been studied in a comprehensive and systematic way. The objective of this study was to conduct a systematic review of the effects of biomedical informatics applications in pediatric chronic diseases.

Methods: A comprehensive literature search was conducted using MEDLINE, the Cochrane Library and EMBASE databases from inception of each database to September 2008. We included studies of any methodological type and any language that applied biomedical informatics to chronic conditions in children and adolescents 18 years of age or younger. Two independent reviewers carried out study selection and data extraction. Quality assessment was performed using a study design evaluation instrument to appraise the strength of the studies and their methodological adequacy. Because of heterogeneity in the conditions and outcomes we studied, a formal meta-analysis was not performed.

Results: Based on our search strategy, 655 titles and abstracts were reviewed. From this set we identified 27 relevant articles that met our inclusion criteria. The results from these studies indicated that biomedical informatics applications have favourable clinical and patient outcomes including, but not limited to, reduced number of emergency room visits, improved knowledge on disease management, and enhanced satisfaction. Seventy percent of reviewed papers were published after year $2000,89 \%$ of users were patients and II\% were either providers or caregivers. The majority $(96 \%)$ of the selected studies reported improved outcomes.

Conclusion: Published studies suggested positive impacts of informatics predominantly in pediatric asthma. As electronic tools become more widely adopted, there will be opportunities to improve patient care in a wide range of chronic illnesses through informatics solutions.
\end{abstract}




\section{Background}

Chronic diseases, defined by the US Centers for Disease Control and Prevention (CDCP) as "illnesses that are prolonged, do not resolve spontaneously and are rarely cured completely", are responsible for two thirds of deaths worldwide [1]. It is estimated that more than 100 million people in North America live with one or more chronic illnesses, consuming more than $75 \%$ of the total health care resources [2]. The number of people with chronic illness is on the rise. It is estimated that by 2020, about 157 million people in North America (50\% of the population), including children and adolescents, will be living with at least one chronic condition [3].

Chronic conditions in children have long-term effect on society, as they progress into adults with increasing demands for health care and disability programs, and decreasing participation in the work force as well as poor quality of life [4]. These chronic conditions cause stress on children and their families. Moreover, substantial amounts of time, energy and personal resources are required to cope with the physical and emotional burden [5]. National Health Interview Surveys on Disability from 1994-1995 indicated that $15 \%$ to $18 \%$ of children and adolescents in the USA were affected by some type of chronic conditions [4].

The rapid development and penetration of information and communication technologies (ICTs) has created opportunities for innovative ways to reduce the societal burden created by chronic diseases in children [6]. ehealth, also known as health or biomedical informatics, is an evolving field, which strives for the acquisition, maintenance, retrieval and application of knowledge and information in health care science, services, research, and education to improve patient care [7].

To the best of our knowledge, there are no published systematic reviews on the role of biomedical informatics in the management of pediatric chronic diseases.

Previous systematic reviews of adult chronic disease have examined applications of home tele-monitoring [8], and information systems [2]. Pare et al [8] specifically studied tele-monitoring and Dorr et al [2] combined chronic conditions that are common in children. We included a wider range of interventions and reported effects on chronic diseases such as asthma and ADHD that are more common in children. In addition, Sanders et al [9] investigated one specific chronic disease, asthma. However, there appears to have been no systematic reviews providing a comprehensive review of a broad range of applications for both physical and mental chronic illnesses in pediatric settings. This study sought to fill this gap.

\section{Methods \\ Search Strategy}

We searched Medline (1950-September 2008), EMBASE (1982-September 2008), and the Cochrane database of systematic reviews (2008) for relevant studies using terms related to computer technology applications in pediatric chronic disease management. Each search required the presence of selected chronic diseases such as asthma, diabetes or autism in combination with any of the following terms: "medical informatics", "informatics", "decision support", or "computer assisted instruction" (detailed search strategy is available upon request).

\section{Study selection}

We focused on studies evaluating applications of any web or computer-based information and communication technology designed to aid the clinical care of chronic illnesses in pediatric settings. We targeted studies that described or appraised a computer-based intervention or application to support clinical care of physical or mental chronic conditions. These included applications or systems used to diagnose or detect symptoms; applications that prevent or monitor symptoms; decision support systems, alert and reminder systems; and patient-centered education applications. Studies were included if (i) the participants were 18 years age or younger; (ii) there was a chronic condition present; (iii) there was at least one computer-based intervention; and (iv) there was a comparison between at least two groups. There was no restriction by language or publication status for inclusion in this systematic review.

Two reviewers (FM and RM) independently reviewed the titles and abstracts of publications identified by the search strategy and assessed each paper as either potentially relevant or not relevant based on study type, study design, subjects, setting, and intervention. The full text publication of a citation thought to be potentially relevant by either reviewer was retrieved. The reviewers independently verified the eligibility of the chosen articles. Disagreement between the two reviewers was resolved by consensus and in some cases by discussing with a third reviewer (JB).

\section{Data Extraction and Quality Assessment}

Data were extracted using a structured data collection form we designed (this is available upon request). Data extracted included: author(s); date of publication; details of the intervention and control; details of participants; outcome measures reported in the primary studies; study duration; and summary measures such as mean, standard deviation and number of participants for the main outcome variable. In studies reporting more than one outcome measure, data were extracted for the primary outcome. Data were initially extracted by one reviewer 
(FM) and verified by the second reviewer (RM). Reporting adequacy was evaluated using an instrument that uses five criteria to identify potential causes of biases $[9,10]$ : i) Formation of study groups-allocation of subjects between the control and intervention groups, ii) Unit of allocation and analysis, iii) Baseline differences between study groups, iv) Type of outcome measure, and v) Completeness of follow-up. A score of 0 to 2 was assigned to each criterion. Then, the scores were summed to give an overall assessment ranging from 0 representing the greatest potential for bias to 10 representing the least [9].

We further examined the characteristics of the studies by clinical setting (inpatient, outpatient, emergency department, patient home, multi-clinical settings or no settings), primary users (patients, healthcare professionals, parents, educators, or administrators), the target patient popula- tion, and the type of primary outcome variable. Outcome measures were considered either clinical (rates of emergency visits and hospitalization, dosage of drugs, symptom reduction and patient's quality of life) or non-clinical (patient education, knowledge and behavior, and adherence to protocols) [9].

\section{Results}

\section{Description of Studies}

MEDLINE and EMBASE search yielded 655 potentially relevant articles. From this set, a total of 27 publications met our inclusion criteria and were selected for review. Figure 1 provides a summary of the study selection process. Most of these studies (70\%) were published after year 2000 and among studies that reported participants' gender, only one study did not include female participants. The age of participants ranged from one to eighteen years

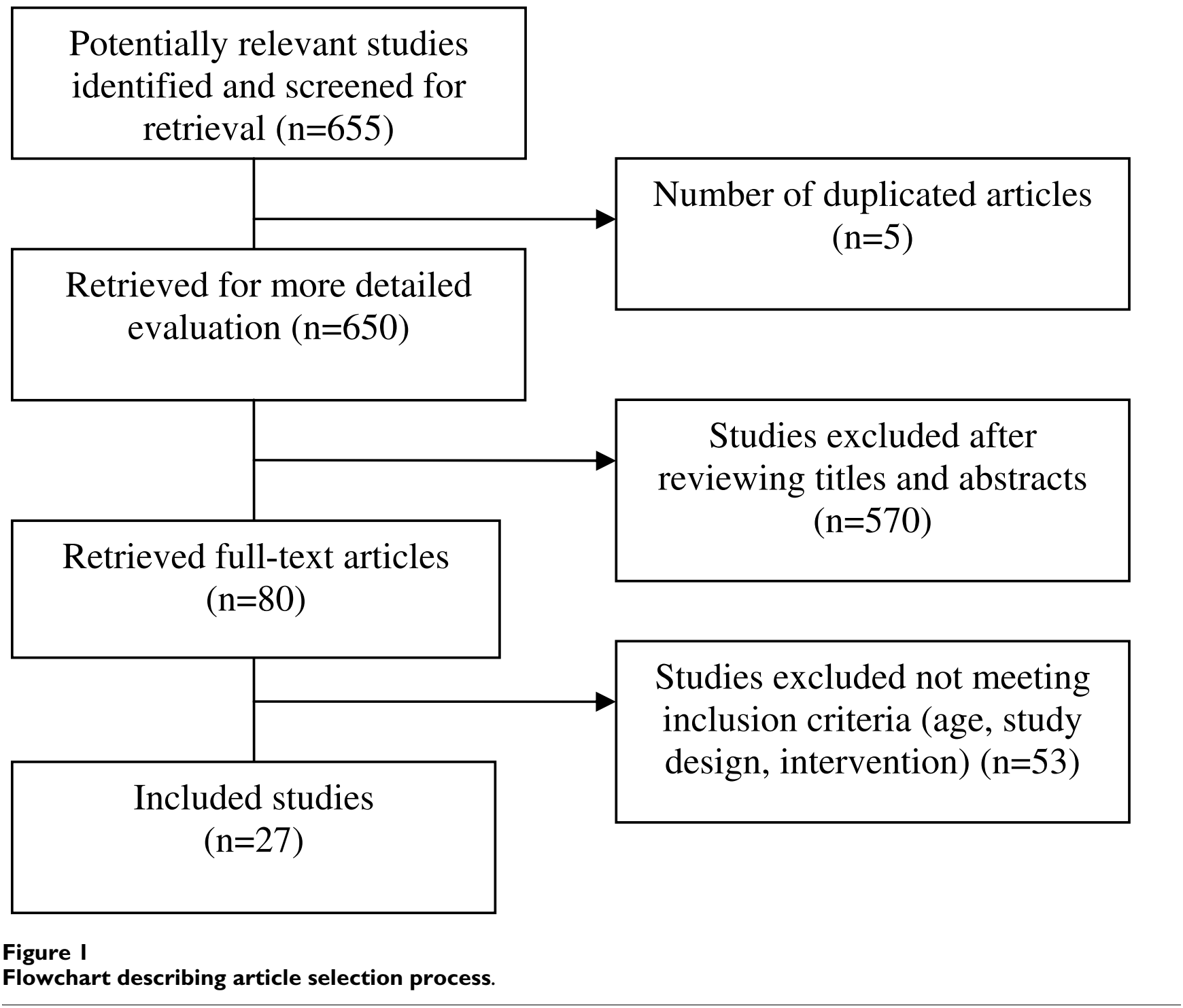


and almost all studies were quantitative with randomized, matched case-control, case crossover study designs. The mean and range of methodological adequacy scores for studies in the various chronic medical conditions were as follows: asthma 6.1 (4-8), cognitive disability 7.8 (6-9), autism 5 (4-7), pediatric oncology 6 (6-6), diabetes 6 (4$8)$, and other studies 7.5 (7-8). Selected publications evaluated the impact of applications on both clinical and non-clinical patient outcomes. Most studies (86\%) took place in an outpatient environment. Eighty nine percent of users were patients and $11 \%$ were either providers or caregivers. Not all studies reported duration of intervention or follow up. Among those that reported them, the duration of the interventions ranged from 20 minutes to several weeks, while the duration of studies ranged from 4 days to 2 years. The majority (96\%) of the selected studies reported improved outcomes. Additional file 1 displays the characteristics of the studies included in the systematic review.

\section{Asthma (8 Studies)}

Chan et al [11] found improvement in quality of life, reduction in emergency department and hospital visits, infrequent rescue therapy and a high level of satisfaction with home telemonitoring. Shegog et al [12] showed significant improvement in knowledge and asthma selfmanagement using a prospective pretest-posttest randomized intervention trial. Increase in knowledge of asthma self-management, reduction in emergency room visits and fewer hospitalizations were reported in relation to the computer game 'Watch, Discover, Think and Act' by Bartholomew et al [13]. This study showed that children using the program scored significantly higher on questions on steps of self-regulation, prevention and treatment strategies. Those children also demonstrated greater selfefficacy compared to children who did not use the program. Huss et al [14] conducted a randomized control trial in 7 to 12 year old children to evaluate the effects of a computer-assisted instructional game on asthma symptoms such as coughing, wheezing, shortness of breath, nighttime awakenings. However, no significant differences have been observed in any of the asthma symptoms before and after intervention between the two groups.

McPherson [15] undertook a pilot study and demonstrated increased knowledge about triggers of asthma after using the computer-assisted program known as 'The Asthma File'. This study further indicated that children are able to extract relevant information from multimedia sources when they are encouraged to participate actively in their learning. Porter et al [16] reported that deployment of a parent-driven decision support system may improve quality of asthma care and patient satisfaction. Krishna et al [17] conducted a randomized controlled trial and reported a significant increase in asthma knowledge of children and their caregivers; decrease in asthma symptom days ( 81 days vs. 51 days per year); and decrease in number of emergency department visits ( 1.93 vs. 0.62 per year) through the use of an internet-based multimedia asthma education program. Krishna et al [17] also showed that the intervention group used a significantly lower average daily dose of inhaled corticosteroids (434 vs. 754 micro gram). Homer et al [18] demonstrated that computerized education programs substantially reduced emergency department and office visits as well as improved asthma-related knowledge.

\section{Cognitive Disability (7 studies)}

Seven studies assessed the impact of applications on mental disabilities such as ADHD (attention deficit hyperactivity disorder); dyslexia; learning and behavior problems; and learning disabilities. Interventions considered in the studies were computerized training of working memory [19], visual hemisphere-specific stimulation [20], and software for computer-delivered instruction [21], computer-based reading [22], computerized study guide [23], computer-assisted mathematics computation drill-downpractice [24], and computer-assisted instructional software [25]. These studies also focused on outcome measures such as neuropsychological assessments [19], substantive errors, fragmentations, and reading time [20], compliance, visual discrimination task, and collateral behavior [21], spelling skill, and reading skill [22], multiple choice reading passage tests, note taking [23], computation skills in addition, subtraction, multiplication, and division [24], and multiple choice tests [25]. Improvements and significant treatment effects were reported in relation to reduction in symptoms of inattention and hyperactivity/impulsivity and improvement for the spanboard task, working memory deficits, response inhibition, and complex reasoning [25]. Other reported improvements included fewer substantive errors and more fragmentations on a text-reading task compare to control group [20], improved accuracy and fluency during reading and spelling [22], improvement in math computation performance over time [24], higher quiz scores and higher overall test scores for a computer study guide group compared to a lecture group [25].

\section{Autism (9 studies)}

Results from a study by Bernard-Opitz et al [26] demonstrated significant improvement in vocal imitations when participants used computer-assisted instruction instead of traditional play interactions. Williams et al [27] found that computer-instructed learning is more effective than book based learning, and children with autism spend more time on reading material when they access it through computer compared to equivalent materials in book format. Findings from another study by BernardOpitz et al [28] suggested that computer-assisted instruc- 
tion is effective in teaching problem-solving skills to children with autism. It also showed that normal and autistic preschool children can be taught social problem solving skills using animated solutions presented by a computer. Swettenham [29] reported that computerized instruction programs are effective in enhancing cognitive functions. Moore et al [30] suggest that participants who received computer-assisted instruction program were more attentive, motivated and learned more vocabulary words than those who received teacher-presented behavioral treatment.

Stenens et al [31] showed that six weeks of high-intensity training with a computerized intervention program (originally designed to improve language skills) influenced neural mechanisms of selective auditory attention in children with language impairment. In another study, these authors showed that computer-based problem solving instructional programs significantly improved math and problem solving ability of students with learning disabilities [32]. Kast et al [33] showed that a three-month computer-based training significantly improved the writing skills of children with and without developmental dyslexia. A significant impact of a computerized progressive attention training program on improving reading comprehension and passage copying of children with ADHD is shown by Shalev et al [34].

\section{Pediatric oncology (3 Studies)}

In a before-and-after study conducted in an academic medical centre from 2001 to 2004, Kim et al [35] showed a significant reduction in ordering errors in pediatric chemotherapy through the use of a computerized provider order entry system. Other studies showed a reduction in prescription errors of chemotherapy dosage using a web-based decision-support system (Leukemia Intervention Scheduling and Advice, 'LISA") [36]; and improved patient education with a computer-assisted instructional program [37].

\section{Diabetes (2 studies)}

Zahlmann et al [38] found a significant decrease in $\mathrm{HbA}_{1 \mathrm{c}}$ values with a decision support system ('DIABETEX') and Horan et al [39] reported a significant improvement in the level of blood glucose with the use of a computer-assisted system designed to promote self-management of insulin.

\section{Other Studies (3)}

Other researchers looked at patients with bronchiolitis, headache or juvenile idiopathic, and brain injury. The studies described the use of interventions such as clinical evidence modules integrated into computerized provider order entry [40]; electronic diaries [41] and web-based interactive interventions [42].
Other studies showed benefits associated with a computerized provider order entry on the frequency of ordering antibiotics, bronchodilators and corticosteroids [40]; increase in the return rates and accuracy of records using electronic diaries [41], and improvement in child antisocial behavior problems and reduction in conflict with parents in relation to school issues using a web-based intervention [42].

\section{Discussion}

Our findings suggest that information and communication technologies can indeed improve quality of care and have an overall positive effect on adherence to clinical guidelines; patient knowledge and self-efficacy; decrease rate of emergency room and medical office visits; and improved patient safety through a reduction in errors. However, little is known about the effects of information technology on resource utilization.

As reported by a previous systematic review, there are encouraging results in relation to pediatric asthma [9]. Studies on autism and learning disabilities demonstrated positive effects of computer-assisted programs in behavioral and cognitive outcomes. Our review also suggests that children with chronic diseases from pre-school through high-school age can respond positively to computerbased education and disease management programs. For children, guardians and health care providers who participated in the reviewed studies, computer-based interventions were effective in improving health care behavior and health care outcomes, in enhancing knowledge and communication with parents and health care providers, and in reducing the need for urgent medical care. This is consistent with findings of systematic reviews of studies including adults with chronic conditions $[2,43,44]$.

Computer-based intervention studies have also been reported to be effective in preventing obesity. Frenn et al [45] examined the effectiveness of internet/video delivered intervention to increase physical activity and reduce dietary fat among low-income, seventh-grade students with various cultural backgrounds. The findings of this study further add to the body of literature suggesting that computer-based interventions are effective in improving health behaviors in middle school students.

The studies available seem to support, consistently, that patient education and disease management can be facilitated through computer-assisted programs and health care related websites. Moreover, these comprehensive interventions are effective in engaging patients and in improving their health and well-being. Others have also demonstrated that when individuals with chronic disease receive effective and coordinated care on an ongoing 
basis, the need for costly emergency room visits and hospital admissions reduce significantly.

The results of this systematic review suffer from some limitations. For example, a key issue that cannot be addressed with the available data is whether or not the knowledge uptake from the various applications improved soon after initiation of the intervention, and also whether or not there is long-term impact. Longitudinal studies over extended periods of time are required to answer such questions. Also some of the outcome variables such as reduced ED visit and lower dose of medications will need to be adjusted for potential confounders (e.g., disease severity, concomitant medications, and so on). This information is generally not reported.

Reviews of the medical informatics literature pertaining to the treatment of adults with chronic conditions suggest that human factors are at least as important as the technological elements powering the intervention itself. For our study, the majority of users of health informatics interventions were school age children who either directly used computers or the Internet, or who were directly exposed to interventions in several short sessions at school. Issues related to human factors were not discussed in any detail in the papers reviewed.

\section{Conclusion}

In conclusion, our systematic review has revealed several important applications of biomedical informatics in pediatric chronic diseases. Published studies suggested positive impacts of informatics predominantly in pediatric asthma. Our review has also highlighted important future directions for research. It is clear, for instance, that rigorous studies are needed to gain a better understanding of the role of informatics in inpatient settings, as well as their impact on workflows, organizational structures, health professional and patient roles, costs and equitable access to health services among members of disadvantaged communities.

\section{Competing interests}

The authors declare that they have no competing interests.

\section{Authors' contributions}

FM contributed to the design of the study, acquisition, analysis and interpretation of data and drafted the manuscript. RM contributed to the design of the study, acquisition, analysis and interpretation of data and helped draft the manuscript. ARJ, JSH and TT helped with interpretation of data and critical revision of the manuscript for important intellectual content. JB conceived the study and contributed to the design of the study, analysis and interpretation of data and helped draft the manuscript. All authors have read and approved the final manuscript.

\section{Additional material}

\section{Additional file 1}

Table 1. Characteristics of included studies.

Click here for file

[http://www.biomedcentral.com/content/supplementary/1472-

6947-9-22-S1.doc]

\section{Acknowledgements}

We would like to gratefully acknowledge a seed grant support provided by the Research Institute of the Hospital for Sick Children for the establishment of the Biostatistics Methodology Unit (BMU). We also gratefully acknowledge insightful comments of two reviewers. ARJ was supported through the Rose Family Chair in Supportive Care, and the Canada Research Chair in eHealth Innovation, which he holds.

\section{References}

I. World Health Organization: Chronic Disease Fact Sheet 2005 [http:// www.who.int/chp/chronic disease report/contents/partl.pdf].

2. Dorr D, Bonner LM, Cohen AN, Shoai RS, Perrin R, Chaney E, Young AS: Informatics systems to promote improved care for chronic illness: a literature review. J Am Med Inform Assoc 2007, 14:156-163.

3. Wolff JL, Starfield B, Anderson G: Prevalence, expenditures, and complications of multiple chronic conditions in the elderly. Arch Intern Med 2002, 162:2269-2276.

4. Perrin JM, Bloom SR, Gortmaker SL: The increase of childhood chronic conditions in the United States. JAMA 2007, 297:2755-2759.

5. Haydon Emma, Roerecke Michael, Giesbrecht Norman, Rehm Jürgen, Kobus-Matthews Marianne: Chronic Disease in Ontario and Canada: Determinants, Risk Factors and Prevention Priorities. [http://www.ocdpa.on.ca/docs/CDP-SummaryReportMar06.pdf].

6. Wyatt JC, Liu JLY: Basic concepts in medical informatics. (Glossary). Journal of Epidemiology \& Community Health 2002, 56:808-8I3.

7. Friedman C: Medical Informatics: Challenges and Opportunities. Center for Biomedical Informatics: Introductory Lecture Series 1996.

8. Pare G, Jaana M, Sicotte C: Systematic review of home telemonitoring for chronic diseases: the evidence base. J Am Med Inform Assoc 2007, 14:269-277.

9. Sanders DL, Aronsky D: Biomedical informatics applications for asthma care: a systematic review. J Am Med Inform Assoc 2006, 13:418-427.

10. Hunt DL, Haynes RB, Hanna SE, Smith K: Effects of computerbased clinical decision support systems on physician performance and patient outcomes: a systematic review. JAMA 1998, 280:1339-1346.

II. Chan DS, Callahan CW, Sheets SJ, Moreno CN, Malone FJ: An Internet-based store-and-forward video home telehealth system for improving asthma outcomes in children. American Journal of Health-System Pharmacy 2003, 60:1976-1981.

12. Shegog R, Bartholomew LK, Parcel GS, Sockrider MM, Masse L, Abramson SL: Impact of a computer-assisted education program on factors related to asthma self-management behavior. Journal of the American Medical Informatics Association 200I, 8:49-56.

13. Bartholomew LK, Shegog R, Parcel GS, Gold RS, Fernandez M, Czyzewski DI, Sockrider MM, Berlin N: Watch, Discover, Think, and Act: a model for patient education program development. Patient Education \& Counseling 2000, 39:253-268.

14. Huss K, Winkelstein M, Nanda J, Naumann PL, Sloand ED, Huss RW: Computer game for inner-city children does not improve asthma outcomes. Journal of Pediatric Health Care 2003, 17:72-78.

15. McPherson A, Forster D, Glazebrook C, Smyth A: The asthma files: evaluation of a multimedia package for children's asthma education. Paediatric Nursing 2002, 14:32-35. 
16. Porter SC, Cai Z, Gribbons W, Goldmann DA, Kohane IS: The asthma kiosk: a patient-centered technology for collaborative decision support in the emergency department. Journal of the American Medical Informatics Association 2004, I I:458-567.

17. Krishna S, Francisco BD, Balas EA, Konig P, Graff GR, Madsen RW: Internet-enabled interactive multimedia asthma education program: a randomized trial. Pediatrics 2003, I I I:503-5 I0.

18. Homer C, Susskind O, Alpert HR, Owusu M, Schneider L, Rappaport LA, Rubin DH: An evaluation of an innovative multimedia educational software program for asthma management: report of a randomized, controlled trial. Pediatrics 2000, 106:210-2/5.

19. Klingberg T, Fernell E, Olesen PJ, Johnson M, Gustafsson P, Dahlstrom $\mathrm{K}$, Gillberg CG, Forssberg $\mathrm{H}$, Westerberg $\mathrm{H}$ : Computerized training of working memory in children with ADHD - a randomized, controlled trial. J Am Acad Child Adolesc Psychiatry 2005, 44:177-186.

20. Van Strien JW, Stolk BD, Zuiker S: Hemisphere-specific treatment of dyslexia subtypes: better reading with anxiety-laden words? J Learn Disabil 1995, 28:30-34.

21. Plienis AJ, Romanczyk RG: Analyses of performance, behavior, and predictors for severely disturbed children: a comparison of adult vs. computer instruction. nalysis and intervention in developmental disabilites 1985, 5:345-356.

22. Van D, Leij $A$ van der: Computer-based reading and spelling practice for children with learning disabilities. J Learn Disabil 1992, 25: 186-195.

23. Horton SV, Lovitt TC, Givens A, Nelson R: Teaching Social Studies to High School Students with Academic Handicaps in a Mainstreamed Setting: effects of a computerized study guide. J Learn Disabil 1989, 22: I02-107.

24. Fuchs $L S, B a h r C M$, Rieth $\mathrm{HJ}$ : Effects of goal structures and performance contingencies on the math performance of adolescents with learning disabilities. J Learn Disabil 1989, 22:554-560

25. Higgins K, Boone R: Hypertext Computer Study Guides and the Social Studies Achievement of Students with Learning Disabilities, Remedial Students, and Regular Education Students. J Learn Disabil 1990, 23:529-540.

26. Bernard-Opitz V, Sriram N, Sapuan S: Enhancing Vocal Limitations in Children with Autism Using the IBM SpeechViewer. Autism 1999, 3:131-147.

27. Williams C, Wright B, Callaghan G, Coughlan B: Do children with autism learn to read more readily by computer assisted instruction or traditional book methods? A pilot study. Autism: the international journal of research and practice 2002, 6:71-91.

28. Bernard-Opitz V, Sriram N, Nakhoda-Sapuan S: Enhancing socia problem solving in children with autism and normal children through computer-assisted instruction. J Autism Dev Disord 200I, $31: 377-384$

29. Swettenham J: Can children with autism be taught to understand false belief using computers? J Child Psychol Psychiatry 1996 , 37:157-165.

30. Moore $M$, Calvert S: Brief report: vocabulary acquisition for children with autism: teacher or computer instruction. J Autism Dev Disord 2000, 30:359-362.

31. Stevens C, Fanning J, Coch D, Sanders L, Neville H: Neural mechanisms of selective auditory attention are enhanced by computerized training: Electrophysiological evidence from language-impaired and typically developing children. Brain Research 2008, 1 205:55-69.

32. Miranda-Casas A, Marco-Taverner R, Soriano-Ferrer M, Melià de Alba A, Simó-Casañ P: [The application of new technologies to solving maths problems for students with learning disabilities: the 'underwater school']. Revista de neurologia 2008, 46(Suppl I):S59-S63.

33. Kast M, Meyer M, Vogeli C, Gross M, Jancke L: Computer-based multisensory learning in children with developmental dyslexia. Restor Neurol Neurosci 2007, 25:355-369.

34. Shalev L, Tsal Y, Mevorach C: Computerized progressive attentional training (CPAT) program: Effective direct intervention for children with ADHD. Child Neuropsychology 2007 , 13:382-388.

35. Kim GR, Chen AR, Arceci RJ, Mitchell SH, Kokoszka KM, Daniel D, Lehmann CU: Error reduction in pediatric chemotherapy: computerized order entry and failure modes and effects analysis. Arch Pediatr Adolesc Med 2006, 160:495-498.
36. Bury J, Hurt C, Roy A, Cheesman L, Bradburn M, Cross S, Fox J, Saha V: LISA: a web-based decision-support system for trial management of childhood acute lymphoblastic leukaemia. $\mathrm{Br} J$ Haematol 2005, 129:746-754.

37. Petersen $\mathrm{M}$ : What are blood counts? A computer-assisted program for pediatric patients. Pediatr Nurs 1996, 22:2I-25.

38. Zahlmann G, Franczykova M, Henning G, Strube M, Huttl I, Hummel I, Bruns W: DIABETEX - a decision support system for therapy of type I diabetic patients. Computer Methods \& Programs in Biomedicine 1990, 32:297-30I.

39. Horan PP, Yarborough MC, Besigel G, Carlson DR: Computerassisted self-control of diabetes by adolescents. Diabetes Educator 1990, 16:205-211.

40. King WJ, Le Saux N, Sampson M, Gaboury I, Norris M, Moher D: Effect of point of care information on inpatient management of bronchiolitis. BMC Pediatr 2007, 7:4.

41. Palermo TM, Valenzuela D, Stork PP: A randomized trial of electronic versus paper pain diaries in children: impact on compliance, accuracy, and acceptability. Pain 2004, 107:213-219.

42. Wade SL, Wolfe CR, Pestian JP, Brown T: Can a Web-Based Family Problem-Solving Intervention Work for Children with Traumatic Brain Injury? Rehabilitation Psychology 2005, 50:337-345

43. Chaudhry B, Wang J, Wu S, Maglione M, Mojica W, Roth E, Morton SC, Shekelle PG: Systematic Review: Impact of Health Information Technology on Quality, Efficiency, and Costs of Medical Care. Ann Intern Med 2006, 144:742-752.

44. Celler BG, Lovell NH, Basilakis J: Using information technology to improve the management of chronic disease. Medical Journal of Australia 2003, 179:242-246.

45. Frenn M, Malin S, Brown RL, Greer Y, Fox J, Greer J, Smyczek S: Changing the tide: an Internet/video exercise and low-fat diet intervention with middle-school students. Applied Nursing Research 2005, | 8: |3-2|.

\section{Pre-publication history}

The pre-publication history for this paper can be accessed here:

http://www.biomedcentral.com/1472-6947/9/22/prepub
Publish with Bio Med Central and every scientist can read your work free of charge

"BioMed Central will be the most significant development for disseminating the results of biomedical research in our lifetime. "

Sir Paul Nurse, Cancer Research UK

Your research papers will be:

- available free of charge to the entire biomedical community

- peer reviewed and published immediately upon acceptance

- cited in PubMed and archived on PubMed Central

- yours - you keep the copyright

Submit your manuscript here

http://www.biomedcentral.com/info/publishing_adv.asp
BioMedcentral 